\section{French Physics Looks Ahead}

Two new initiatives affecting the development of physics in France were announced by Professor P. Léna, the President of the French Physical Society, at Physique 89 , the 74 th in the series of annual exhibitions organised by the Society, which was held at the Villepinte Parc des Expositions to the north of Paris on 4-8th December 1989. The occasion was especially appropriate because the presentation of recent activities and products by industry, and by some of the large national and European research organisations located mainly in France, illustrated the increasing significance of some current trends in the development, teaching and public perception of physics in Europe.

Before announcing the new initiatives, Professor Léna outlined the more important issues. He cited the need to modernise scientific equipment in the universities since this had been neglected somewhat in recent years owing to the emphasis on the large research facilities. In relation to the instrumentation industry itself, he noted that the emergence of the European market was already bringing about restructuring, a process that is being accelerated by Community programmes such as Eureka which favour the competitive exploitation of science and technology irrespective of national boundaries. Industry's concerns in the area of vocational training were also raised. The President noted that it appears to be necessary to increase the number of people in industry who receive formal training in research to bring the number to equal the level in the FRG where it is about twice that in France.

The first of the new initiatives arises directly from a current trend throughout physics to exploit developments in data and image handling techniques that were stimulated by the need to economise on the operating costs of large physics experiments by using powerful computer-based technologies. In becoming more easily available, these data acquisition, treatment and visualisation methods are starting to help enormously in the way physicists communicate, and to revitalise the perception of physics by the public. The French Physical Society is aiming to promote the appreciation of the richness of today's images in physics by launching a Commission headed by Thierry Montmerle of the Commissariat à I'Energie Atomique (CEA) entitled "Images de la Physique"'.
The second initiative is the setting up of another Commission called "Physique et Entreprise" (Physics and Industry) charged with analysing and reporting upon the strategic role of physics in the development of industry. The Society and the Association Nationale de la Recherche Technique (ANRT) have recently agreed to collaborate in the Commission which will be chaired by a prominent physicist having strong links to industry and whose name will probably be announced within two months. Its tasks will be to some extent modelled upon those of the Scientific and Technical Mission on optics in France that produced the "Rapport Jerphagnon" in 1985. They will cover a variety of crucial issues including the future role and skill requirements of physicists in industry and institutions, the relevance of research and development activities in the so-called "non-competitive" sector, modes of cooperation, intellectual property rights and the amount of training required at the interdisciplinary and European levels. The work will, it is hoped, complement a more global analysis called "La Recherche et Entreprise" (Research and Industry) that is being carried out by the Ministry of Research and Technology.

Professor Léna emphasised that the new initiatives follow upon some earlier ones that have already been translated into proposals and actions for enhancing physics in France. In the field of research training, the French Physical Society has strongly supported the creation of the new three-year Ph.D. programme equivalent to those operating in the Federal Republic of Germany, the United Kingdom, Holland, Italy and Sweden. The Minister of Research and Technology has already budgeted for a doubling within five years in the number of doctorate students from 3500 (with some 500 in physics) to 7000 , in line with the proposals made in a report submitted in June 1989 by B. Decomps and G. Aubert entitled "Propositions de Rénovation du Système d'Aides à la Formation par la Recherche". It is planned that the increase will meet the needs of both industry and the public sector, notably the larger national research organizations which will start to replace significant proportions of their staffs in the 1990's. Laboratories in the two sectors will have to be mobilised if the objective is to be met so it is anticipated that the number of CIFRE contracts for joint industry/university research will also have roughly to double from about 500 (in 1988 ) to 1000 by 1995 . With regard to the teaching of physics at the secondary and higher levels, the report of the Commission "Perspectives d'avenir" by Pierre Berge was submitted to the Education Minister in October 1989 and the Society is now hoping for commitments in areas such as the modernisation of laboratory equipment. A jump in the quality of scientific and technical education is, one might say, imperative and the Society is clearly seeking progress on several fronts involving teaching, graduate training, industrial development and public awareness. The EPS will be following the results of the initiatives since they obviously have implications for the development of physics at the European level.

\section{AEA Technology}

Research in the United Kingdom Atomic Energy Authority is from April 1990 no longer to be organised along establishment lines. A matrix structure is to be put into force based on nine "businesses". These are: thermal reactors; fast reactors; fusion; contract R\&D; decommissioning and waste management; nuclear fuel cycle technology; environmental protection services; oi and gas technology; risk management technology. The objective is to turn the old AEA into a new contract orientated organisation expressed in its new name AEA Technology. The aim is to provide customers world-wide with specialised technical services and advanced engineering expertise.

No doubt much of the work in the nuclear power field will go on as before even if the names of the contracting parties change, but it has already been announced that expenditure on fast reactors and on fusion research is to be drastically cut and the decision to exclude nuclear power stations from electricity privatization further emphasises the low priority now being given to nuclear energy. In order to try and capitalize on past investments in advanced technology it is intended that a much more entrepreneurial spirit will be established and that greater encouragement will be given to revenue earning enterprises.

Although fusion, an activity directly related to physics, is singled out as a business (under D.R. Sweetman) it is notable that its primary task is to support JET and the establishment of Culham is being integrated into Harwell. Harwell itself is home to none of the other businesses which some will feel will fragment further the establishment - a process that has been going on these many years now.

It remains to be seen whether industry and institutions overseas are able to provide all the research and development work that will be needed to keep the work force at its present strength or whether the changes will initiate a steady decline in staff. Physicists will be watching developments with some anxiety. 